\title{
Epidemiological Study of Different Syndromes in 300 Deaf and Mute Children
}

\author{
Bhushan Kathuria ${ }^{1}$, Himani Dhingra ${ }^{2}$, Dinesh Madhur ${ }^{3}$, Vikrant Kamboj ${ }^{4}$, Sharad Hernot ${ }^{5}$, Sachin Kadam $^{6}$, Rigved Nittala ${ }^{7}$, \\ Mohit Pareek ${ }^{8}$
}

\begin{abstract}
Objective: To study the epidemiological aspects of syndromic hearing loss (HL) in deaf and mute children below 15 years of age.

Materials and methods: The study "Epidemiological study of different syndromes in 300 deaf and mute children" was conducted on 300 deaf and mute children below 15 years of age at Rohtak (Haryana) from August 2013 to July 2014. Three hundred deaf and mute candidates were included in the study from various schools for deaf and mute children in the Rohtak city and deaf and mute children attended the ENT outdoor at the Department of Otolaryngology and Head and Neck Surgery, Pandit Bhagwat Dayal Sharma Post Graduate Institute of Medical Sciences, Rohtak, Haryana, India, for the evaluation of their deafness. Information regarding patient's age, sex, religion, age of presentation, residence, family history of deafness, consanguineous marriage in the family, socioeconomical status of the family, literacy and occupation of the parents, and developmental history of the candidate was recorded from the parents and guardians using a standard questionnaire. Audiological tests were done to determine the type and the degree of $\mathrm{HL}$.

Results: Out of 300 deaf and mute children, syndromic HL was found in 44 cases (14.66\%). Most common systems involved in syndromic HL were ocular in eight patients (18.18\%) followed by skeletal in four patients (9.09\%) and craniofacial malformation in four cases (9.09\%). Out of 300 deaf and mute cases, well-recognized syndromes were found in five cases (1.66\%) and the most common syndrome found was Waardenburg's syndrome (2 cases). In the 44 syndromic HL cases, 36 patients were males (81.81\%) and 8 patients were females (18.18\%). Out of 44 syndromic $\mathrm{HL}$ cases, 42 (95.45\%) were Hindu by religion and 2 (4.54\%) were Muslim. Residence wise, 20 patients (45.45\%) were from a rural area and 24 patients (54.54\%) were from an urban area. Out of 44 syndromic $\mathrm{HL}$ cases, fathers were illiterate in 5 cases $(11.36 \%)$, while mothers were illiterate in 23 cases (52.27\%), while fathers were educated in 39 cases (88.63\%) and mothers were educated in 21 cases (47.72\%). By occupation, fathers were laborers in 25 cases (56.81\%) and mothers were housewives in 38 cases (86.36\%). Socioeconomically, 31 patients $(70.45 \%)$ were from the lower-middle and middle socioeconomical status, while 11 cases (13.63\%) were from the lower socioeconomical status. History of consanguineous marriage was present in two cases (4.54\%). Both these cases were Hindu by religion. Family history (genetic etiology) of HL was present in six cases (13.63\%) and acquired cases were found in nine cases (20.45\%). In 29 cases (65.90\%), no etiology was found.

Conclusion: From the above results, we can see that syndromic $\mathrm{HL}$ is more common in the male urban child. Mothers who are illiterate and housewife are a risk factor for deafness. Syndromic HL is more common in the lower and lower-middle socioeconomical status families. Any newborn with ocular skeletal and craniofacial abnormalities should be urgently evaluated for deafness.
\end{abstract}

Keywords: Childhood deafness, Deafness epidemiological profile, Syndromic hearing loss.

International Journal of Head and Neck Surgery (2020): 10.5005/jp-journals-10001-1354

\section{INTRODUCTION}

In 2005, the WHO estimated that there are 278 million people worldwide with bilateral moderate to profound hearing loss $(\mathrm{HL})$, of whom, 62 million have deafness. Two-thirds of people with moderate to severe HL live in the developing country. Genetic causes are the most common cause of HL in the developed countries. Syndromic forms constitute about one-third of genetic $\mathrm{HL}$ and remaining two-thirds form nonsyndromic HL. Among the nonsyndromic $\mathrm{HL}$, a large majority (70-80\%) of cases are autosomal recessive often characterized by being profound and prelingual. Autosomal dominant forms tend to present later and results in progressive postlingual $\mathrm{HL}$.

We are trying to discuss deafness briefly in a stepwise manner, first various classifications of deafness, then various causes of deafness, and lastly evaluation and management of a deaf child.

\section{Materials and Methods}

The study "Epidemiological study of different syndromes in 300 deaf and mute children" was conducted on 300 deaf and mute children below 15 years of age at Rohtak (Haryana). The study was conducted from August 2013 to July 2014.
1,3,5,8 Department of Otolaryngology and Head and Neck Surgery, Pandit Bhagwat Dayal Sharma Post Graduate Institute of Medical Sciences, Rohtak, Haryana, India

${ }^{2}$ Department of Paediatrics, King Edward Memorial Hospital, Mumbai, Maharashtra, India

${ }^{4}$ Department of Otolaryngology and Head and Neck Surgery, Kasturba Medical College, Mangaluru, Karnataka, India

${ }^{6}$ Department of General Surgery, Government Medial College, Surat, Gujarat, India

${ }^{7}$ Department of General Surgery, Alluri Sitaram Raju Academy of Medical Sciences, Eluru, Andhra Pradesh, India

Corresponding Author: Bhushan Kathuria, Department of Otolaryngology and Head and Neck Surgery, Pandit Bhagwat Dayal Sharma Post Graduate Institute of Medical Sciences, Rohtak, Haryana, India, Phone: +91 7015671278, e-mail: Kathuriabhushan56@gmail.com How to cite this article: Kathuria B, Dhingra H, Madhur D, et al. Epidemiological Study of Different Syndromes in 300 Deaf and Mute Children. Int J Head Neck Surg 2020;11(1):1-5.

Source of support: Nil

Conflict of interest: None

(0) The Author(s). 2020 Open Access This article is distributed under the terms of the Creative Commons Attribution 4.0 International License (https://creativecommons. org/licenses/by-nc/4.0/), which permits unrestricted use, distribution, and non-commercial reproduction in any medium, provided you give appropriate credit to the original author(s) and the source, provide a link to the Creative Commons license, and indicate if changes were made. The Creative Commons Public Domain Dedication waiver (http://creativecommons.org/publicdomain/zero/1.0/) applies to the data made available in this article, unless otherwise stated. 
Three hundred deaf and mute candidates included in the study were from various schools for deaf and mute children in the Rohtak city and deaf and mute children attending ENT outdoor at Pt. Bd Sharma PGIMS, Rohtak, Haryana, for the evaluation of their deafness.

Information regarding patient's age, sex, religion, age of presentation, residence, family history of deafness, consanguineous marriage in the family, socioeconomical status of the family, literacy, and occupation of the parents and developmental history of the candidate was recorded from the parents and guardians using a standard questionnaire. Developmental history of the children would include prenatal, perinatal, and postnatal history of the candidate.

Inclusion criteria for the candidate were all deaf and mute children below 15 years of age. Exclusion criteria used were children who were complaining only $\mathrm{HL}$ without any speech and language problems like who were suffering from serous otitis media, acute and chronic otitis media, and other common causes of HL. Audiological tests would be done to determine the type and the degree of $\mathrm{HL}$.

Audiological tests included were pure tone audiometery, otoacoustic emissions (OAEs), auditory brainstem response (ABR) testing [audiological tests would be brainstem auditory evoked response (BAER), brainstem evoked response (BSER)].

Blood investigations and imaging study were done whenever necessary. Consent for history taking, clinical examination, and any intervention was taken from parents and guardians of the candidate.

\section{Results}

The study included a total of 300 deaf and mute children, out of which, 236 cases were from various schools for deaf and mute at the Rohtak city, Haryana, and 64 cases were those who came to ENT OPD for the evaluation of their deafness.

From the data, we can see that nonsyndromic $\mathrm{HL}$ is much more common than syndromic HL (Table 1).

The role of various epidemiological factors in syndromic and nonsyndromic HL that were observed in our study are listed below.

In the present study, we found that age-wise distribution of deaf and mute children in both groups was the same. The syndromic

Table 1: Type of hearing loss in our study

\begin{tabular}{llcc}
\hline S. no. & Type of hearing loss & Number of cases & Percentage \\
\hline 1 & Syndromic & 44 & 14.66 \\
2 & Nonsyndromic & 256 & 85.33 \\
3 & Total & 300 & 100 \\
\hline
\end{tabular}

Table 2: Age of presentation (AOP)

\begin{tabular}{lllllll}
\hline & & \multicolumn{3}{c}{$\begin{array}{c}\text { Syndromic hearing } \\
\text { loss }\end{array}$} & & \multicolumn{2}{c}{$\begin{array}{c}\text { Nonsyndromic hearing } \\
\text { loss }\end{array}$} \\
\cline { 7 - 8 } \cline { 6 - 7 } \cline { 6 - 7 } S. no. & $\begin{array}{l}\text { AOP } \\
\text { (years) }\end{array}$ & No. of cases & Percentage & & No. of cases & Percentage \\
\hline 1 & $0-1$ & 19 & 43.18 & & 83 & 32.42 \\
2 & $1-2$ & 13 & 29.55 & & 68 & 26.56 \\
3 & $2-3$ & 7 & 15.91 & & 45 & 17.58 \\
4 & $3-4$ & 3 & 6.82 & & 30 & 11.72 \\
5 & $4-5$ & 1 & 2.27 & & 18 & 7.03 \\
6 & $5-6$ & 1 & 2.27 & & 8 & 3.13 \\
7 & $6-7$ & 0 & 0.00 & & 2 & 0.78 \\
8 & $7-8$ & 0 & 0.00 & & 2 & 0.78 \\
Total & & 44 & 100.00 & & 256.00 & 100.00 \\
\hline
\end{tabular}

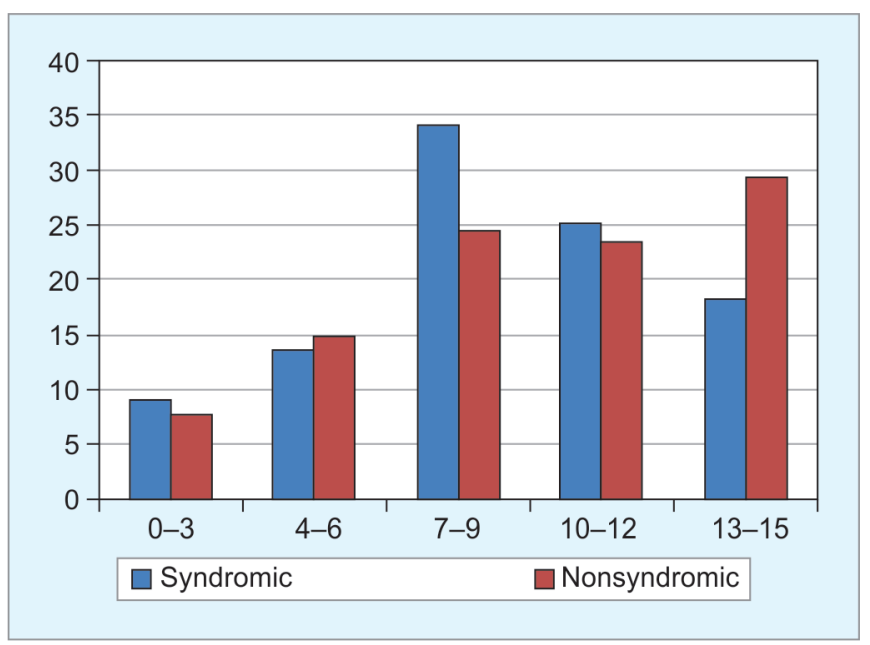

Fig. 1: Age wise distribution of cases in our study

HL group cases presented slightly earlier (first 3 years) than the nonsyndromic HL group (88.63\% vs $76.56 \%$ ) (Table 2 and Fig. 1).

The sex ratio in both syndromic HL (36 vs 8 ) and nonsyndromic $\mathrm{HL}$ (203 vs 53) groups was almost the same (approximately 4:1) (Table 3 and Fig. 2).

This shows that urban deaf and mute cases got slightly more accessibility to schools for deaf and mute children (Table 4). This shows that lower socioeconomic status of the parents is highly associated with deafness (Table 5).

Out of 16 Muslim cases, consanguineous marriage was found in 10 cases $(62.5 \%)$, and out of 283 Hindu cases, consanguineous marriage was found in 8 cases $(2.82 \%)$. This shows that consanguineous marriage in the Muslim community is strongly associated with $\mathrm{HL}$ (Table 6).

Table 3: Sex wise distribution of the cases in our study

\begin{tabular}{llccllc}
\hline & & \multicolumn{2}{c}{$\begin{array}{c}\text { Nonsyndromic hearing } \\
\text { loss }\end{array}$} & & \multicolumn{2}{c}{$\begin{array}{c}\text { Syndromic hearing } \\
\text { loss }\end{array}$} \\
\cline { 3 - 4 } \cline { 6 - 7 } & & No. of & & & No. of \\
S. no. & Sex & subjects & Percentage & & subjects & Percentage \\
\hline 1 & Male & 203 & 79.30 & & 36 & 81.82 \\
2 & Female & 53 & 20.70 & & 8 & 18.18 \\
Total & & 256 & 100.00 & & 44.00 & 100.00 \\
\hline
\end{tabular}

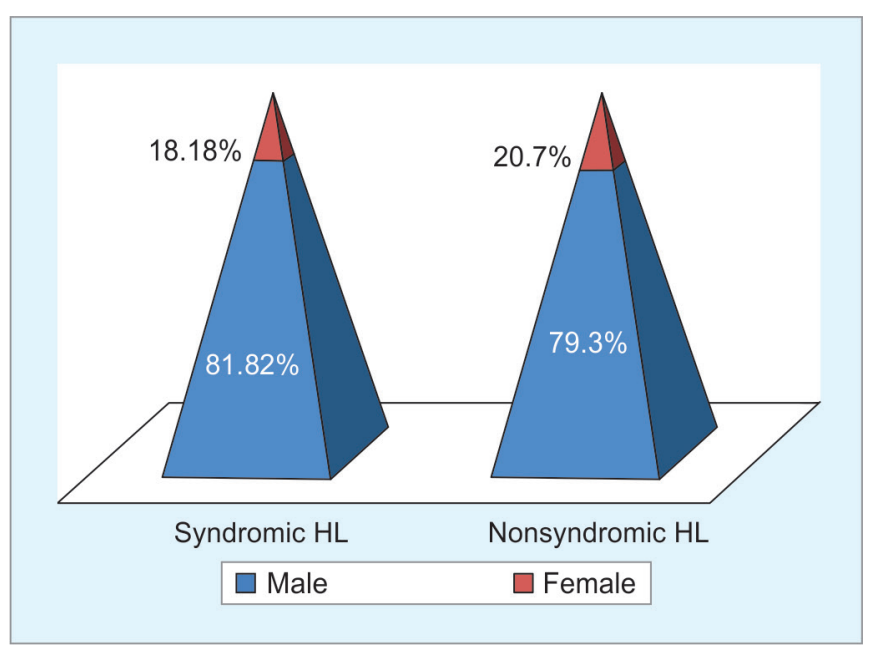

Fig. 2: Sex distribution syndromic and nonsyndromic hearing loss 
Epidemiological Study of Different Syndromes in 300 Deaf and Mute Children

Table 4: Residence wise distribution of cases

\begin{tabular}{llll}
\hline & & \multicolumn{1}{c}{$\begin{array}{c}\text { Nonsyndromic } \\
\text { hearing loss }\end{array}$} & \multicolumn{1}{c}{$\begin{array}{c}\text { Syndromic } \\
\text { hearing loss }\end{array}$} \\
\cline { 3 - 4 } S. no. & Residence & No. of subjects (\%) & No. of subjects (\%) \\
\hline 1 & Urban & $152(59.38)$ & $24(55.55)$ \\
2 & Rural & $104(40.62)$ & $20(45.45)$ \\
Total & & $256(100)$ & $44(100)$ \\
\hline
\end{tabular}

Table 5: Socioeconomic status wise distribution of cases

\begin{tabular}{|c|c|c|c|c|c|}
\hline \multirow[b]{2}{*}{ S. no. } & \multirow[b]{2}{*}{$\begin{array}{l}\text { Economical } \\
\text { status }\end{array}$} & \multicolumn{2}{|c|}{$\begin{array}{c}\text { Nonsyndromic } \\
\text { hearing loss }\end{array}$} & \multicolumn{2}{|c|}{$\begin{array}{c}\text { Syndromic } \\
\text { hearing loss }\end{array}$} \\
\hline & & $\begin{array}{l}\text { No. of } \\
\text { cases }\end{array}$ & Percentage & No. of cases & Percentage \\
\hline 1 & Lower & 71 & 27.73 & 11 & 25.00 \\
\hline 2 & Lower middle & 173 & 67.58 & 25 & 56.82 \\
\hline 3 & Middle & 12 & 4.69 & 6 & 13.64 \\
\hline 4 & Higher & 0 & 0.00 & 2 & 4.55 \\
\hline Total & & 256 & 100.00 & 44 & 100 \\
\hline
\end{tabular}

Table 6: Role of marital status of parents in hearing loss

\begin{tabular}{|c|c|c|c|c|}
\hline \multicolumn{5}{|c|}{ Role of consanguineous marriage in various groups } \\
\hline S. no. & Group & $\begin{array}{l}\text { Total } \\
\text { case }\end{array}$ & $\begin{array}{l}\text { Consanguineous } \\
\text { marriage }\end{array}$ & Percentage \\
\hline 1 & Syndromic & 44 & 2 & 4.54 \\
\hline 2 & Nonsyndromic & 256 & 16 & 6.25 \\
\hline Total & & 300 & 18 & 6.00 \\
\hline
\end{tabular}

Table 7: Role of family history in hearing loss

\begin{tabular}{llccc}
\hline & & \multicolumn{3}{c}{ Family history } \\
S.no. & Group & No. of cases & present & Percentage \\
\hline 1 & Syndromic HL & 44 & 6 & 13.64 \\
2 & Nonsyndromic HL & 256 & 22 & 8.59 \\
Total & & 300 & 28 & 9.33 \\
\hline
\end{tabular}

Family history was present in approximately $10 \%$ in both syndromic $\mathrm{HL}$ and nonsyndromic $\mathrm{HL}$ groups (Table 7). Maternal illiteracy is strongly associated with congenital HL (Table 8). Most of these cases had a history of hospital/ICU admission for their management (Table 9).

We found typical syndromes in just $1.66 \%$ of cases with the most common being the Waardenburg syndrome $(0.66 \%)$. Treacher Collins syndrome and Congenital rubella syndrome were found in $0.33 \%$ cases each (Table 10 ) so that an early diagnosis of deafness can be suspected and intervention can be done as early as possible.

Table 8: Paternal education wise distribution of cases

\begin{tabular}{|c|c|c|c|c|c|}
\hline \multirow[b]{2}{*}{ S. no. } & \multirow[b]{2}{*}{ Literacy } & \multicolumn{2}{|c|}{$\begin{array}{c}\text { Nonsyndromic } \\
\text { hearing loss }\end{array}$} & \multicolumn{2}{|c|}{$\begin{array}{l}\text { Syndromic } \\
\text { hearing loss }\end{array}$} \\
\hline & & $\begin{array}{l}\text { No. of } \\
\text { cases }\end{array}$ & Percentage & No. of cases & Percentage \\
\hline 1 & Illiterate & 51 & 19.92 & 5 & 11.36 \\
\hline 2 & Graduate & 35 & 13.67 & 7 & 15.90 \\
\hline 3 & Other & 170 & 66.40 & 32 & 72.72 \\
\hline Total & & 256 & 100 & 44 & 100 \\
\hline
\end{tabular}

Table 9: Acquired causes of hearing loss

\begin{tabular}{|c|c|c|c|c|c|}
\hline S. no. & Causes & & $\begin{array}{l}\text { Syndromic } \\
\text { HL (44) }\end{array}$ & $\begin{array}{l}\text { Nonsyn- } \\
\text { dromic } \\
\text { HL (256) }\end{array}$ & $\begin{array}{l}\text { Total deaf } \\
\text { and mute } \\
\text { cases (300) }\end{array}$ \\
\hline \multirow[t]{3}{*}{1} & Perinatal & Anoxia & 2 & 5 & 7 \\
\hline & & LBW & 3 & 8 & 11 \\
\hline & & Kernicterus & 0 & 3 & 3 \\
\hline \multirow[t]{2}{*}{2} & Prenatal & Infection & 1 & 0 & 1 \\
\hline & & Drug intake & 2 & 6 & 8 \\
\hline 3 & Postnatal & Meningitis & 1 & 11 & 12 \\
\hline Total & & & 9 & 33 & 42 \\
\hline
\end{tabular}

Table 10: Typical syndromic hearing loss

\begin{tabular}{llll}
\hline S.no. & Syndrome & No. of cases & Percentage (out of 300) \\
\hline 1 & Waardenburg & 2 & 0.66 \\
2 & Treacher Collins & 1 & 0.33 \\
3 & Mental retardation & 1 & 0.33 \\
4 & Rubella syndrome & 1 & 0.33 \\
Total & & 5 & 1.66 \\
\hline
\end{tabular}

\section{Discussion}

Deafness is defined as the disability of using hearing as the primary channel for receiving speech even with amplification. ${ }^{1} \mathrm{HL}$, hence, affects various related aspects of child's overall development as the development of speech and language is impaired. It also hampers the child's social and emotional relationship. ${ }^{2}$

Deafness is found to occur in 1 per 1000 live births, and almost $50 \%$ of congenital deafness is hereditary. ${ }^{3}$ Over $70 \%$ congenital sensorineural hearing impairment are nonsyndromic, while about $30 \%$ are associated with other defects. ${ }^{4}$

Reddy et al. conducted their study on 743 children and found syndromic HL in 138 (18.57\%) and nonsyndromic in 605 (81.43\%). ${ }^{5}$

All India Institute of Medical Sciences in a report of 110 cases $^{6}$ for cochlear implant reported syndromic $\mathrm{HL}$ in $4.5 \%$ of cases and nonsyndromic $\mathrm{HL}$ in $46.4 \%$ of cases. $^{6}$

Mozaria et al. reported an incidence of syndromic $\mathrm{HL}$ in $3.5 \%$ of cases. Genetic HL may appear as a part of syndrome. ${ }^{7}$

In the present study conducted in 300 deaf and mute children, we found 44 cases of syndromic $\mathrm{HL}$, which constitutes $14.66 \%$ of the study population (Table 1). Out of 44 syndromic HL cases, 10 cases were those who came to our department for the evaluation of their deafness, while the rest of the cases were from various schools for deaf and mute children. Only 10 cases were below 6 years of age, while a majority of cases (34 (77.27\%)) were between 6 and 15 years of age. Reddy et al. also found a similar age distribution in their study. ${ }^{5}$

A study done by Elango et al. found that $\mathrm{HL}$ was diagnosed in only $19 \%$ of children by the age of 2 years. ${ }^{8}$ Tschopp observed that hearing handicap was recognized at an average age of 2 years. ${ }^{9}$

In the syndromic HL group, only 2 cases (4.54\%) presented before the age of 6 months, 19 cases (43.18\%) presented within the first year of age, 13 cases (29.54\%) presented during 1-2 years of age, and 7 cases (15.9\%) during 2-3 years of age. In our study, we found that 39 cases (88.63\%) presented before 3 years of age and all cases (44) presented before 6 years of age (Table 2 and Fig. 1).

It is found that if diagnosis and intervention take place before 6 months of age, an almost age-appropriate level of language skill can 
be established. So in 2009, the Joint Committee on infant hearing has endorsed Universal Newborn Hearing Screening (UNHS). The aims of UNHS are to provide hearing screening to all newborns before the age of 1 month, confirmation of $\mathrm{HL}$ in infants who do not pass the initial or a subsequent screening, through an audiologic evaluation by the age of 3 months so that comprehensive treatment can be initiated before the age of 6 months.

We also observed that a majority of patients [36 (81.81\%)] were males, while only 8 (18.18\%) were females, which may be due to social negligence toward the female sex (Table 3 and Fig. 2). Reddy et al. observed that syndromic deafness is more common in boys $54.35 \%$, while girls constituted $45.65 \% .^{5}$

Clifton and Swart in a study with 169 children found that a majority of cases were boys. ${ }^{10}$ Zazouk also found an increased risk of deafness with male sex. ${ }^{11}$ However, Walch et al. found the male to female ratio of approximately $1: 1 .^{12}$

In our study, we found that syndromic hearing is more common in the lower middle (56.82\%) followed by the lower (25\%) socioeconomic group (Table 5). Reddy et al. in their study found that syndromic $\mathrm{HL}$ is more common in the lower middle $(42.03 \%)$ followed by the middle (31.88\%) socioeconomic status population group. ${ }^{5}$ Bafeqeeh et al. found that lower socioeconomical status family condition tended to have a higher rate of hearing impairment than the middle and the upper class. ${ }^{13}$ Ashoor in a study of schoolchildren found that hearing impairment is more frequent in middle-class families with a relatively large family size.

In our study, we found a history of parental consanguineous marriage in just 2 (4.54\%) patients, both of them Hindus (Table 6). However, Reddy et al. found a history of consanguineous marriage in $78(57.52 \%)$ out of 138 cases, while 68 (43.48\%) cases were products of non-consanguineous marriage. ${ }^{5}$ Zlotogra and Barges in their study found that children born to consanguineous married couples were at a higher risk for deafness. Zazouk also observed that consanguinity is a risk factor for HL. ${ }^{11}$

We found the family history of deafness in six (13.63\%) children with syndromic HL which indicates genetically inherited disorder (Table 7). Reddy et al. found that deafness was genetically inherited in $15.77 \%$ of cases. ${ }^{5}$

In our study, we found that fathers were illiterate in $11.36 \%$ of cases, while in $88.64 \%$ of cases, fathers were educated. This shows that most of the educated parents allowed their children for admission in schools for deaf and mute children. We also observed that in $52.27 \%$ of cases, mothers were illiterate. This shows that maternal illiteracy is strongly associated with congenital $\mathrm{HL}$ (Table 8).

Bafeqeeh et al. found paternal illiteracy in $7.1 \%$ of cases and maternal illiteracy in $39.3 \%$ of cases. Their study revealed that parental education was an important demographic factor in the possession of deafness. ${ }^{13}$ Reddy et al. found paternal illiteracy in about $47.83 \%$ of cases which is similar to our study. ${ }^{5}$

In our study, acquired causes were present in nine (20.45\%) cases. History of birth asphyxia was present in two cases, low birth weight in three cases, maternal drug intake in two cases, meningitis in one case, and one case presented with the Rubella syndrome. However, we could not find any specific cause in 29 (65.90\%) cases (Table 9).

Reddy et al. found that acquired causes were present in $13.77 \%$ of cases and, in $71.01 \%$ of cases, no specific cause could be established. ${ }^{5}$ Clifton and Swart observed a family history of deafness in one-tenth of cases and, also in $30 \%$ of cases, no apparent cause

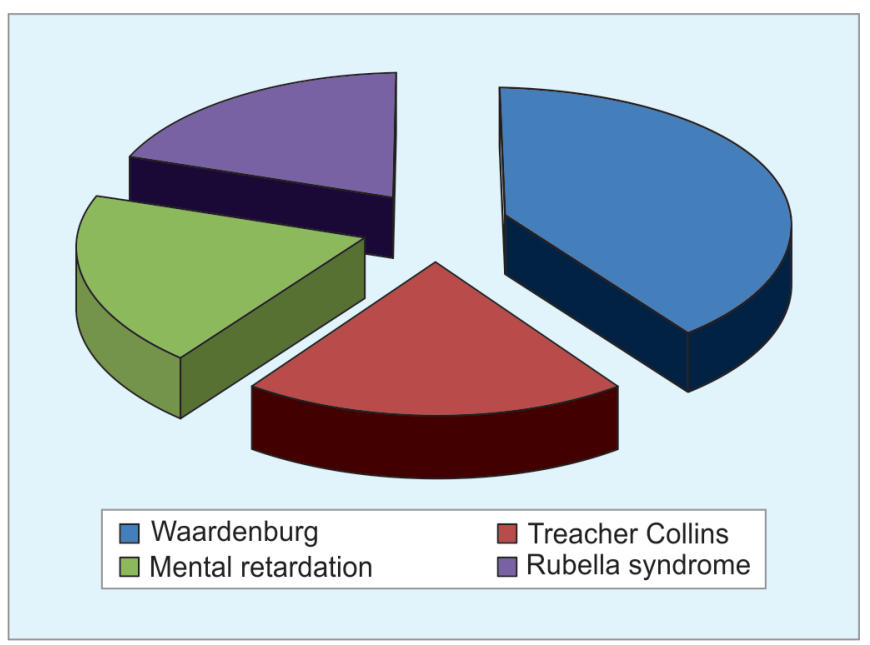

Fig. 3: Typical syndromic hearing loss

could be established. ${ }^{10}$ Elango et al. reported acquired deafness in $35 \%$ of cases. They could not establish the cause in $28.4 \%$ of cases. ${ }^{8}$ Morzaria et al. found that common causes of bilateral sensorineural HL were idiopathic (41.5\%), genetic nonsyndromic (27.2\%), prenatal $(11.5 \%)$, perinatal $(9.7 \%)$, postnatal $(6.6 \%)$, and genetic syndromic $(3.5 \%){ }^{7}$

In our study, the most common system involved was the ocular system (18.18\%) followed by craniofacial (9.09\%). Deafness was cryptogenic in $50 \%$ of cases. Reddy et al. found ocular involvement in $24.46 \%$ of cases followed by skeletal involvement as the most common system involved in syndromic HL. ${ }^{5}$ Sutton and Rowe observed a high proportion of craniofacial abnormalities in children with hearing impairment and counted it to be a risk factor for deafness. $^{14}$

We found typical syndromes in just $1.66 \%$ of cases with the most common being the Waardenburg syndrome ( $0.66 \%)$. Treacher Collins syndrome and congenital rubella syndrome were found in $0.33 \%$ of cases each (Table 10 ).

Reddy et al. found well-recognized syndromes in $3.21 \%$ of cases, the common ones were the Waardenburg syndrome $(0.67 \%)$ and severe myopia syndrome (0.67\%). Others were Pendred syndrome $(0.4 \%)$, mental retardation $(0.4 \%)$, Usher's syndrome $(0.27 \%)$, and Jervell and Lange-Nielsen syndrome $(0.13 \%)^{5}$ (Fig. 3).

\section{Conclusion}

To diagnose the typical syndrome, we need an additional genetic study as most of the clinical features of syndromic HL may not be present at the time of presentation and also various syndromes show variable expressivity and penetrance. There is also a need to carry out further epidemiological studies on deafness so that there can be early identification of inherited syndromes and, thus, we will be able to provide adequate genetic counseling to parents.

\section{References}

1. Gorlin RJ, Toriello H, et al. Hereditary hearing loss and its syndrome. New York: Oxford University Press; 1996.

2. Dallapiccola B, Mingarelli R, et al. Genetic aspects of deafness. Acta Otolaryngol Ital 1996;16:79-90.

3. Cantani A. Genetic causes of hearing loss in chidren. Paditr Padol 1989;24:321-330. 
4. Kumar A, Dhanda R. The identification and management of deaf children. Indian J Pediatr 1997;64:785-792. DOI: 10.1007/BF02725500.

5. Reddy MVV, Sathyanarayana V, et al. Epidemiological study on children with syndromic hearing loss. Indian J Otolaryngol And Head and Neck Surg 2004;56(3):208-212. DOI: 10.1007/BF02974352.

6. Venkatakarthikeyan C, Kapil S, et al. Etiology of sensorineural hearing loss in children undergoing cochlear implantation. Ind J Otol 2007;13:10-13.

7. Morzaria S, Westerberg BD, et al. Systematic review of etiology of bilateral sensorineural hearing loss in children. Int J Pediatr Otolaryngol 2004;68:1193-1198. DOI: 10.1016/j.ijporl.2004.04.013.

8. Elango S, Chand RP, et al. Childhood deafness in Malaysia. Int J Paeditr Otolaryngol 1992;24:11-17. DOI: 10.1016/0165-5876(92) 90061-S.

9. Tschopp K. Hearing disorder in childhood. Ther UMsch 1993;50:619-626.
10. Clifton NA, Swart JG. Profile analysis in a school for black deaf children. A pilot study. S Afr Med J 1998;73:289-290.

11. Zazouk SM. Epidemiology and etiology of hearing impairement among infants and children in a developing country. J Otolaryngol 1997;26:335-344.

12. Walch C, Kole W. Bilateral sensorineural hearing disorder in children: Etiology of deafness and evaluation of hearing tests. Int J Pediatr Otolaryngol 2000;53:31-38. DOI: 10.1016/S01655876(00)00307-4.

13. Bafeqeeh SA, Zauzok S, et al. Relevant demographic factor and hearing impairement in Saudi children:Epidemiological study. J Laryngol Otol 1994;108:294-298. DOI: 10.1017/S002221510012-6581.

14. Sutton GJ, Rowe S. Risk factors for childhood sensorineural hearing loss in the oxford region. Br J Audiol 1997;1:39-54. DOI: 10.3109/03005364000000007. 